\title{
Wanted And Unwanted Pregnancy In Early Adolescence: Evidence From A Clinic Population
}

\author{
Constance Lindemann and Wilbur J. Scott \\ University of Oklahoma
}

\begin{abstract}
Data presented here from a university clinic for unwed pregnant early adolescents suggest two paths to pregnancy: (a) some females, though unmarried, apparently want to become pregnant and have a child; (b) others, who do not want a child, nonetheless become pregnant due to unforeseen circumstances. We report some critical differences in reproductive behavior between those who wanted to get pregnant and those who did not. Implications are developed for theorizing about early adolescent pregnancy and for delivering pregnancy related services for teenagers.
\end{abstract}

This study draws into question the key issue of "intent" in the adolescent literature on early adolescent pregnancy. It is readily apparent from a review of this literature that researchers lack consensus about the motivations of early adolescent females who become pregnant. One body of research indicates that, either because of psychological proclivity (Thomas, 1967; Vincent, 1961; Young, 1945) or of socio-cultural background (Rainwater, 1966; Roberts, 1966; Rodman, 1963), unmarried adolescent females who become pregnant basically wanted to have a child or at least were not opposed to the idea. However, another body of research indicates that unmarried young women ordinarily become pregnant without having intended to do so and would have preferred to have successfully avoided pregnancy (Furstenberg, 1976; Lindemann, 1974; Zelnik \& Kantner, 1979).

In this article we suggest that each explanation represents a separate "track" leading to motherhood in early adolescence. Further, we attempt to determine if

We wish to thank Dr. Willis Wingert, Director, Public Health Nurse Joan Howard, and Health Aides Juanda DeShone, Mary Jones, Dora Jordan, Becky Quiroz, and Petra Rodriquez of the Pregnant Teen Project, Los Angeles County/University of Southern California Medical Center. 
there are differences in reproductive behavior between those who wanted to get pregnant and those who did not want to get pregnant. Our study of patients in a clinic for low income early adolescents who are pregnant shows that a sizable proportion of early adolescents do appear to desire motherhood prior to conception and that those who do are different in important ways from those who unintentionally acquire the role of mother. These findings contain significant implications for theorizing about early adolescent pregnancy and for the delivery of services for pregnant teenagers.

\section{THE ISSUE OF INTENT}

A good deal of previous research develops and defends the position that teenagers who become pregnant do so because, regardless of whether or not they are able to articulate the reasons, they want a child. For example, psychoanalytic theories commonly suggest that the desire for pregnancy is an unconscious psychodynamic phenomenon. Young (1945) emphasizes "the purposefulness of the girl's behavior, her determination, however unconscious, to have not just a baby, but specifically a baby out of wedlock' (p. 82). The basis for many theories of this type is Freud's thesis that pregnancy fulfills a young woman's unconscious desire for a penis and for sexual relations with her father. Other psychological theories indicate that pregnancy is a means of achieving psychological needs such as love and recognition (Thomas, 1967; Vincent, 1961). In this view, females who have a psychological need, usually for a love object or symbol, seek sexual relations in hopes of having a child and believe that the child will fulfill this need.

Some sociological theories, by viewing illegitimacy as an artifact of the social system in which the adolescent is socialized, likewise support the position that illegitimate pregnancy to a large extent is intended. In particular, girls of lower socioeconomic status often are said to acquire attitudes and beliefs which minimize the social consequences of, or even provide positive sanctions for, having illegitimate babies during adolescence (Rainwater, 1966; Roberts, 1966). The implication is that these teenagers are conforming to, rather than deviating from, the normative constraints of their immediate social setting by becoming pregnant. According to Rodman (1963), these value differences primarily represent an adaptive response to the circumstances of poverty, i.e., persons of lower socioeconomic status do share dominant values regarding sex and reproduction but "stretch" these values in coping with circumstances in which they live.

Contrary to this broad tradition, which emphasizes that adolescent illegitimate pregnancies are in some form intentional, other studies advance the argument that teenage pregnancy basically is a matter of "bad luck" or bad judgment. For instance, in her ethnographic study of a clinic for pregnant teenagers, Lindemann (1974) reports finding no differences in previous birth control behavior between teenage females requesting birth control services and those requesting pregnancy counseling or abortion information. Both groups had experienced nonmarital coitus on a number of occasions before defining themselves as sexually active and, hence, before confronting in "real life" terms the potential for procreation and mother- 
hood. In the process, some became pregnant and others did not. Likewise, Furstenberg's (1976) research raises questions concerning advance commitment to motherhood. He contends:

Commitment to motherhood need not always precede the fact. An alternative, but equally plausible, assumption is that most women who become unwed mothers do not set out to have a child out of wedlock ... Rather than being directed or drawn to it (as previous theories of illegitimacy have postulated) most women 'drift' into adolescent motherhood (p. 39).

Given these two bodies of evidence, it may well be, as Paulkner (1969) suggests, that "one explanation... will not cover the entire group of women involved." Perhaps there are two "tracks" leading to illegitimate pregnancy among adolescents. If so, there should be two categories of pregnant adolescents (and adolescent mothers): (1) those who, for psychological or social reasons, were predisposed toward having a baby and, though unmarried, acted accordingly, and (2) those who would have preferred to have avoided becoming pregnant but "got caught."

Since the dynamics of these categories clearly differ, it is of critical importance to ascertain variations in reproductive behavior between the two groups and to confront these differences both in theorizing about early adolescent pregnancy and in delivering services for pregnant teenagers. Two reproductive behaviors most prominently studied in the adolescent pregnancy literature are the female's knowledge of sex and contraception and her actual pattern of contraceptive use. ${ }^{1}$ Therefore, in this study we compare the level of exposure to sex and birth control information and level of contraceptive use among early adolescents who wanted to get pregnant with corresponding levels of these variables among early adolescents who are pregnant but who did not want to get pregnant.

ANALYSIS

The research setting was a clinic in a university/county health sciences center located in Los Angeles. The center was established to provide comprehensive services for pregnant early adolescents and their families. The sample consists of the pregnant adolescents who used the clinic's services during the mid-1970s. All were referred to the clinic by various agencies in the community or by the university hospital itself. Each early adolescent met the following criteria for treatment: (a) pregnant, (b) under the age of 16 by the due date of delivery, and (c) financial eligibility (meaning that the teenager was from a low income family). These criteria automatically impose controls for socioeconomic status and age.

\footnotetext{
'We use the term "reproductive behavior"' to denote several aspects of reproduction not ordinarily encompassed by the term. Technically, knowledge of sex and contraception is not a reproductive behavior and contraceptive use is not a reproductive behavior. However, we prefer our more general use of the term to the more specific referent of simply patterns of intercourse.
} 
The data are taken from a questionnaire administered routinely by the counseling staff to incoming clients. The measure of the female's orientation toward her own pregnancy is derived from a question concerning whether or not she wanted to get pregnant. Those who said they had wanted to get pregnant, or who indicated they had not cared one way or another, were classified as "wanted pregnancies" and those who said the pregnancy was unwanted as "unwanted pregnancies.", Knowledge of sex and contraception is indicated by questions concerning whether the respondent had ever talked with another person about sex or birth control and questions about the kinds of contraceptive procedures or devices she was aware of, including rhythm, coitus interruptus, condom, pill, suppository, douche, and foam. Questions concerning the prior use of various birth control techniques, including any used at the instance leading to conception, are tapped as measures of contraceptive use.

The sample contains 301 respondents. The mean age for the total sample is $\mathbf{1 5 . 6}$ years. On the average, the females have completed eight years of school. This indicates a lag of about two years since the "usual" grade for that age is the tenth. The mean age of menarche is $\mathbf{1 1 . 9}$ and the mean age at first coitus is approximately two and one-half years later, 14.2. The mean number of boys with whom these females had intercourse is 1.4 , indicating that most were not promiscuous. There were no significant differences in these characteristics between those who had wanted to get pregnant and those who did not want to get pregnant.

Our data suggest that the incidence of wanted pregnancies among low income early adolescents probably is higher than the average incidence of wanted pregnancies for all teenage pregnancies. In this sample, almost two-thirds of the 301 adolescents $(64.1 \%)$ report that they wanted to get pregnant or that they had not cared about it one way or the other. The remaining one-third (35.9\%) assert that they had not wanted to get pregnant. This observed proportion of wanted pregnancies is high in comparison to some recent estimates of intended pregnancies. For instance, Zelnik and Kantner (1979) report that approximately two-thirds of all pregnant teenagers in their broadly based sample did not want to get pregnant. Putting together estimates from these two sources, it appears that possibly as many as one-third of all teenage pregnancies are to some degree intended, but that the percentage may be twice as high for certain subsamples of teenage pregnancies.

The differences in levels of exposure to sex and birth control information and in levels of contraceptive use between females in the sample who wanted to get pregnant and those who did not are summarized in Table 1. In rank order of occurrence, those in the sample talk about matters of sex with sisters or girlfriends, mothers, teachers or school counselors, boyfriends, and nurses or doctors. We do find that those who say they did not want to get pregnant heard and talked about sex and birth control more than those who say they wanted to get pregnant. More adolescents who did not want to get pregnant report having discussed sex $(76.6 \%$ vs. 59.9) and birth control (54.6\% vs. 43.7$)$ with others than those who say they wanted to get pregnant. Those not wanting to get pregnant also are more likely to have discussed sex with their teachers $(36.1 \%$ vs. 27.0$)$, sisters or girlfriends 
TABLE 1

Reproductive Behavior by Wanted and Unwanted Pregnancy

\begin{tabular}{|c|c|c|c|}
\hline \multirow[b]{2}{*}{ Reproductive Behavior } & \multicolumn{2}{|c|}{ Pregnancy ${ }^{a}$} & \multirow[b]{2}{*}{$\mathrm{P}$ of $\chi^{2 b}$} \\
\hline & Wanted & Unwanted & \\
\hline Talked about sex/pregnancy & $59.9 \%$ & $76.6 \%$ & \\
\hline with mother & $27.0 \%$ & $36.1 \%$ & .05 \\
\hline with sister/friend & 42.6 & 56.5 & $<\quad .05$ \\
\hline with boyfriend & 19.3 & 22.4 & ns \\
\hline with teacher/counselor & 21.9 & 26.9 & $<\quad .05$ \\
\hline with nurse/doctor & 13.3 & 14.3 & ns \\
\hline Talked about birth control & $43.7 \%$ & $54.6 \%$ & $<\quad .05$ \\
\hline with mother & $14.9 \%$ & $17.6 \%$ & ns \\
\hline with sister/friend & 30.5 & 38.2 & $<\quad .05$ \\
\hline with boyfriend & 12.6 & 9.9 & ns \\
\hline with teacher/counselor & 14.9 & 12.7 & ns \\
\hline with nurse/doctor & 10.9 & 13.7 & ns \\
\hline $\begin{array}{l}\text { Knowledge of some birth } \\
\text { control technique }\end{array}$ & $75.6 \%$ & $89.7 \%$ & $<.05$ \\
\hline $\begin{array}{l}\text { Use of some birth control } \\
\text { control technique in past }\end{array}$ & $17.8 \%$ & $30.3 \%$ & $<.05$ \\
\hline $\begin{array}{l}\text { Use of birth control technique } \\
\text { at time of conception }\end{array}$ & $5.4 \%$ & $10.4 \%$ & $<\quad .05$ \\
\hline \multicolumn{4}{|c|}{$\begin{array}{l}\text { aWanted pregnancy, } n=193(64.1 \% \text { of total sample); Unwanted pregnancy, } n=108(35.9 \% \\
\text { of total sample) }\end{array}$} \\
\hline${ }^{\mathrm{b}}$ Test of difference between tw & tions. & & \\
\hline
\end{tabular}

( $56.5 \%$ vs. 42.6$)$, or a teacher or counselor $(26.9 \%$ vs. 21.9$)$ and to have talked about birth control with sisters or girlfriends $(38.2 \%$ vs. 30.5$)$ This indicates a critical difference in reproduction behavior between those who wanted to get pregnant and those who did not.

\section{DISCUSSION}

An assumption implicit in much of the teenage pregnancy literature is that an increased awareness of sex and reproduction reduces the likelihood that an unmarried adolescent will become, or will want to become, pregnant. Much of the policy for the prevention of adolescent pregnancy is based on this assumption. Our data, though limited, do provide a basis for informed speculation about this assumption. To begin with, although a larger percentage of respondents who say their pregnancy was unwanted show a knowledge of some birth control technique and report use of 
some method of birth control in the past, the fact remains that all females in the sample are pregnant. If these adolescents truly knew about sex and contraception, then the efficacy of further education and further exposure to information is questionable for this group. Researchers, policy makers and practitioners would then need to ask why adolescents are not utilizing their knowledge more "successfully." In this regard, one should not lose sight of the obvious fact that sex provides more than simply the opportunity for conception. Hence, birth control information is only part of the cost-risk-gain calculus of decision-making concerning sexual behavior in early adolescence. The quality of information and the effectiveness of its implementation is relevant only if the teenager seeks to avoid pregnancy but chooses to engage in sex for other reasons (gains).

However, not all information is accurate and not all contraceptive practices are effective. Lindemann (1974) has shown previously that inaccurate information and ineffective contraceptive use commonly occur when information is obtained from peers. The most frequent source of information for females in the sample is a sister or girlfriend. The least frequently used sources of birth control information are teachers, counselors, nurses, or doctors. On this point, there are no differences between those who wanted to get pregnant and those who did not. In this instance, the research question becomes "would clarification of the information be related to successful prevention of pregnancy?",

The answer to this question is contingent largely upon the issue of intent. We suspect that adolescent females who have not yet come to grips with the issues of sex and reproduction nonetheless have developed underlying preference structures which will influence whether they will or will not want to become (unwed) mothers in early adolescence (cf. Coombs, 1979). The primary issue in prevention then, is, to initiate some conscious confrontation with the issues of pregnancy and motherhood in addition to information and education on sex and contraception. Such a confrontation may increase the level of awareness and conscious choice prior to actually becoming pregnant, instead of after she already is pregnant and the issues can no longer be avoided. (cf. Lindemann, 1974).

The process of information acquisition and conscious confrontation with the issues is most likely to reduce the incidence of unwanted pregnancies. However, it is by no means clear, either from the evidence or from theoretical expectations, that increasing exposure to information and a confrontation with the issues necessarily will change an underlying preference structure favoring wanted pregnancies among unmarried adolescents. Therefore, future research must entertain the possibility that early adolescents who want to become pregnant may be inclined to do so even when they acquire more information about sex and pregnancy and are confronted with the issues of pregnancy and motherhood.

The question still lingers: "why would such a high proportion of teenagers "want" to become pregnant?" The theories we have reviewed emphasize the presence of psychological "needs" or of internalized values conducive to become pregnant. Pregnancy, like any other behavior, may be used to satisfy unmet needs and to negotiate the social environment. It incurs gains which are thought to out- 
weigh costs and risks or to be unobtainable by other available and satisfactory courses of action. Not the least of these gains is the immediate promotion to adult status, including the right to privacy and the right to live independently (cf. Stack, 1974). In particular, pregnancy leads to the one adult role-motherhood-that is clearly and definitively prescribed for women in our society. As a result, pregnancy is perhaps of greater significance for low income teenagers who are not as able as older or higher status women to envision desirable, alternative roles and strategies of action.

\section{CONCLUSION AND POLICY IMPLICATIONS}

The data presented in this study suggest that there are some critical differences in the reproductive behavior of unmarried adolescents who wanted a pregnancy and those who did not. This provides limited evidence that there are two tracks leading to adolescent pregnancy. In one, we suspect pregnancy occurs because a predisposition toward having a baby, even if illegitimate, leads to reproductive behavior conducive to becoming pregnant. In the other, pregnancy results despite preference and behavior. Here a preference for avoiding pregnancy leads to reproductive behavior less conducive to becoming pregnant but, because of bad luck or bad judgment, pregnancy occurs nonetheless.

This conclusion concerning two tracks leading to pregnancy in early adolescence suggests three basic and distinct kinds of intervention strategies. The first strategy is directed toward preventing unwanted pregnancies. A central feature of these efforts aimed at prevention of unwanted pregnancies consists of disseminating information about reproductive physiology and the effective use of birth control. It also may entail the delivery of contraceptive services to adolescents. Intervention strategies of the type have been supported and promoted by policy makers and practitioners for some time (Klerman, 1980). Given that unwanted pregnancies are by definition undersirable to the adolescent, programs of this type are by definition also desirable to the public, except for those segments whose values call for sexual abstinence among the unmarried as well as the avoidance of nonmarital pregnancy.

The second category of intervention strategies involves attempts to convert those who "want" to get pregnant to the position that it is preferable to avoid pregnancy when very young. As we have already suggested, this conversion is not necessarily affected by exposure to increasing information concerning sex and reproduction. Intervention strategies in these cases face the task of introducing those females not yet pregnant, but who have a predisposition toward early pregnancy, to ways of fulfilling their psychological and social needs without having a baby. This is not as simple and straightforward a proposition as it may seem. Motherhood, even in less than desirable circumstances, still tends to carry with it a positive value that leads adolescents to choose it despite the difficulties and hardships that have been well documented in the literature on adolescent pregnancy (Chilman, 1979). As Ryan observes (1971, p. 197): "Motherhood, after all is said and done, is still a pretty good thing; who, indeed, dares knock it in America? Having a baby, legitimate or 
illegitimate, is still a joyful experience; and a two person family, though statistically deviant and economically difficult, is still familial." The adolescents who want and have babies testify to the accuracy of this observation. Finally, having a baby may be not only a desirable option for adolescents; it is also a readily available one.

Converting those who want to get pregnant to the position that it is preferable to avoid pregnancy at very young ages requires intervention strategies directed at the social structure and values of society. These strategies must be addressed to the needs, such as desires for adult status, love, or understanding, that lead to wanting babies in the first place. The adolescents in our sample come from low status backgrounds which typically afford women limited social mobility. Here, as in other segments of the stratification system, a woman traditionally gains status through "her man" and her family. Under these circumstances, it should come as little surprise that a baby, with all its primary and secondary gains, is often a first choice. Changing the orientation of early adolescents who want a baby may require fundamental changes in the opportunity structure for adolescent females as well as for women of all ages who serve as role models for them. This is a difficult chore given the social structure and values entrenching motherhood as the primary role for women. However, one advantage of this kind of strategy is that it need not address primarily the question of sex, pregnancy, and birth control directly. Considering the controversy surrounding the delivery of information and services concerning sex to teenagers, this is a decided advantage.

Finally, the third intervention strategy is directed to those early adolescents who already are pregnant. For this group, intervention requires counseling about abortion, keeping the baby or giving it up for adoption, acquiring health care, making the transition to the role of mother, and minimizing the negative social and economic effects of early pregnancy. With the notable exception of differences in orientation toward these issues which may exist between adolescents who had not wanted to become pregnant and those for whom pregnancy was wanted, the issue of intent at this point become moot. The strategy now becomes one of dealing with the pregnancy, and if the baby is to be kept, learning the mechanisms of effective parenting. Professionals increasingly are becoming attuned to such needs (Klerman, 1980).

An important component of these services which has not been addressed should be the prevention of pregnancy in the infants of early adolescent mothers who are, after all, only 12 years or so away from menarche themselves. Since early pregnancy often repeats itself in generations this strategy may be worthy of attention.

\section{REFERENCES}

Chilman, C. S. Adolescent sexuality in a changing American society. Washington, D.C.: DHEW Publication No. (NIH) 79-1426, 1979.

Coombs, L C. Underlying family-size preferences and reproductive behavior. Studies in Family Planning, 1979, 10, 25-35.

Furstenburg, F. F. Unplanned parenthood. New York: Free Press, 1976. 
Klerman, L. V. Adolescent pregnancy: A new look at a continuing problem. American Journal of Public Health. 1980, 70, 776-778.

Lindemann, C. Birth control and unmarried young women. New York: Springer, 1974.

Paulkner, J. Girls pregnant out of wedlock. In M. LaBarre \& W. LaBarre, (Eds.), The double jeopardy, the triple crisis: Illegitimacy today. New York: National Council on Illegitimacy, 1969.

Rainwater, L. Crucible of identity: The Negro lower-class family. In T. Parsons \& K. Clark (Eds.), The Negro American. Boston: Houghton Mifflin, 1966.

Roberts, R. W. The unwed mother. New York: Harper \& Row, 1966.

Rodman, H. Lower class value stretch. Social Forces. 1963, 42, 205-215.

Ryan, W. Blaming the victim. New York: Vintage Books, 1971.

Stack, C. All our kin. New York: Harper \& Row, 1974.

Thomas, W. I. The unadjusted girl. New York: Harper \& Row, 1967.

Vincent, C. E. Unmarried mothers. New York: Free Press, 1961.

Young, L. Personality patterns in unmarried mothers. In R. W. Roberts (Ed.) The unwed mother. New York: Harper \& Row, 1945, pp. 81-94.

Zelnick, M., \& Kantner, J. F. Reasons for nonuse of contraception by sexually active women aged 15-19. Family Planning Perspectives, 1979, 11, 289-296.

Reprint requests should be addressed to:

Constance Lindemann

School of Social Work

University of Oklahoma

Norman, Oklahoma 73019 